\title{
Solidification Behavior of Intensively Sheared Hypoeutectic Al-Si Alloy Liquid
}

\author{
H.R. Kotadia, N. Hari Babu, H. Zhang, S. Arumuganathar, Z. Fan \\ BCAST (Brunel Centre for Advanced Solidification Technology), Brunel University, Uxbridge, \\ UB8 3PH, UK
}

\begin{abstract}
The effect of the processing temperature on the microstructural and mechanical properties of Al-Si (hypoeutectic) alloys solidified from intensively sheared liquid metal has been investigated systematically. Intensive shearing gives a significant refinement in grain size and intermetallic particle size. It is also observed that the morphology of intermetallics, defect bands and microscopic defects in high pressure die cast components are affected by intensive shearing the liquid metal. We attempt to discuss the possible mechanism for these effects.
\end{abstract}

Keywords: Al-Si alloys; Solidification; HPDC; Intensive shearing. 


\section{INTRODUCTION}

Al-Si casting alloys are increasingly being used in the automotive and aerospace industries for critical structural applications due to their low density, excellent castability, weldability, corrosion resistance and, in particular, good tensile and fatigue properties. ${ }^{[1]}$ The presence of silicon in these cast alloys provides a high fluidity imparted by the presence of a relatively large volume of Al-Si eutectic, which reduces shrinkage during solidification and the coefficient of thermal expansion of the cast products. ${ }^{[2]}$ The mechanical properties of $\mathrm{Al}-\mathrm{Si}$ alloys can be greatly altered by changing the microstructure of the primary $\alpha-\mathrm{Al}$ and the eutectic phase, which can be controlled by the solidification process.

Al-Si alloys are commonly fabricated by a high pressure die cast (HPDC) process due to their high fluidity and a short solidification temperature range. The HPDC process has been extensively explored to meet the demands of modern automobile industries for efficient production and low cost. ${ }^{[3]}$ The microstructure of HPDC produced samples is very complex and it is influenced by many factors associated with liquid and semi-solid melt processing, flow and heat transfer phenomena. ${ }^{[4-6]}$ The general microstructure of HPDC hypoeutectic Al-Si alloy consists of a dendritic primary $\alpha-\mathrm{Al}$ solid solution, surrounded by eutectic regions. The complex geometry of these microstructural features, their locations and arrangements are often nonuniform and usually a strong spatial correlation exists between microstructural features and mechanical properties. A fine and uniform microstructure with minimum casting defects are important to obtain better mechanical properties. Continuous research has been undertaken over the past few years to enhance the mechanical properties by changing the solidification conditions and the mechanisms responsible for the formation of casting defects such as defect bands. A defect band is a common feature observed in HPDC aluminium and magnesium alloys, particularly for thin walled castings. A defect band is characterised by a region consisting of a higher concentration of the eutectic phase, interdendritic porosity, and intermetallic particles. ${ }^{[4-6]}$ These defects are related to the presence of regions of semi-solid mush that have different mechanical properties and they form as a result of shear or the failure of the dendritic network during die filling under high pressure. ${ }^{[5]}$ 
The development of new processing techniques, therefore, becomes an inevitable task for both the materials community and the automobile industry. Intensive shearing by melt conditioning by an advanced shear technology (MCAST) unit is an innovative process developed recently

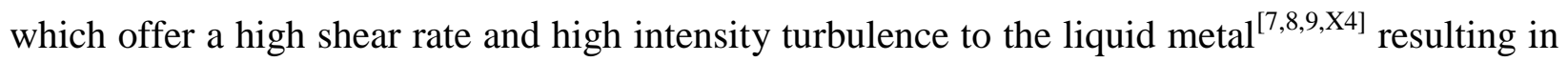
a uniform chemical composition and temperature in the entire volume of liquid. The melt conditioned liquid is subsequently cast to near-net shapes using a conventional cold chamber HPDC machine. It has been found that, magnesium components when produced from melt conditioned liquid in the semi-solid or in the vicinity of the liquidus temperature range, have mechanical properties which are superior to that of conventional HPDC process. ${ }^{[8,10, \mathrm{X} 3]}$ In addition, intensive shearing is an useful method to overcome the detrimental effect of foreign particles on mechanical properties and is expected to play a significant role in recycling of Al alloys. $^{[\mathrm{X} 5]}$

The main objectives of this study are to evaluate the role of applying intensive shearing to the liquid metal on the microstructure in the as-cast condition and to correlate the mechanical properties with the evaluated microstructural observations. In this study, experimental research demonstrated that, when Al-Si alloy liquid is sheared above the liquidus temperature, during solidification it can result in refined microstructure. It was also shown that intensive shearing reduces defect band and porosity by improving primary $\alpha$-Al phase morphology and providing considerable liquid flow between the particles. This study also investigates the effect of intensive shearing on size and morphology of $\alpha-\mathrm{Al}(\mathrm{Fe}, \mathrm{Mn}) \mathrm{Si}$ intermetallic compounds.

\section{EXPERIMENTAL PROCEDURES}

The alloy Al-9.4\%Si (A380), supplied by Norton Aluminium Ltd. with a chemical composition given in Table 1 was used in these experiments. The $6.5 \mathrm{~kg}$ melt was prepared in a clay graphite crucible in an electric resistance furnace. The melt was held $130{ }^{\circ} \mathrm{C}$ above its melting point for $\sim 2$ hours to homogenize the melt. By using graphite rod, dross was removed from the surface of melt and the melt was manually stirred for composition uniformity purpose. Pre-determined melt quantity ( $650 \pm 50 \mathrm{~g}$ ) was transferred to small graphite crucibles for conducting experiments. 
The shearing experiments were carried out in a Melt Conditioning by an Advanced Shear Technology (MCAST) unit which is described elsewhere. ${ }^{[7,8,11,12, \mathrm{X} 4]}$ During the melt conditioned high pressure die casting (MC-HPDC) experiments, the liquid metal was sheared in the MCAST unit prior to transferring to the HPDC unit (DCC280, LK Machinery, Hong Kong), with a 280 tonnes clamping force to produce standard tensile test samples. The dimensions of the tensile test samples are $6.4 \mathrm{~mm}$ in gauge diameter, $25 \mathrm{~mm}$ in gauge length, and $12 \mathrm{~mm}$ in diameter of grip section and full cast component size is $23 \mathrm{~cm}$ length and $32 \mathrm{~cm}$ height. The barrel temperature for the MCAST (temperature at which the shearing was performed) unit was set from 585 to 650 ${ }^{\circ} \mathrm{C}$, the shearing time was set at $60 \mathrm{~s}$, and the shearing speed was set at $500 \mathrm{rpm}$. The experiments were also carried out at all processing temperatures $\left(T_{p}\right)$ using a conventional HPDC process (without shearing) to compare the microstructural and mechanical properties of both set of samples. Processing parameters for the HPDC process are given in Table. 2.

Samples for metallographic examination were cut from the cross section of tensile bar at centre of $6.4 \mathrm{~mm}$ gauge diameter (e.g. Fig. 4a), where cooling rate is $\sim 1000 \mathrm{Ks}^{-1}$. The specimens were mounted in Bakelite, ground with $\mathrm{SiC}$ abrasive paper and polished with a silica suspension. The microstructures were also observed after etching with Keller's (95 ml water, $2.5 \mathrm{ml} \mathrm{HNO}{ }_{3}, 1.5$ $\mathrm{ml} \mathrm{HCI}, 1.0 \mathrm{ml} \mathrm{HF}$ ) reagent. A Zeiss optical microscope (OM) with an Axiocam MRc camera was utilized for the observations and quantitative analyses.

Quantitative metallographic analysis was carried out to analyze the different phases and defects. The gas porosity and primary $\alpha$-Al phase size, $d$ were calculated by:

$d=\sqrt{4 A / \pi}$

and shape factor $(F)$ were calculated by:

$F=4 \pi A / P^{2}$

where, $A$ is the total area and $P$ is the perimeter length of the primary particles. When $F$ is equal to 1 , it represents a perfect spherical particle. To characterize the distribution of the intermetallic particles, the statistical Quadrat method was used. ${ }^{[13]}$ Finally, the mechanical properties were measured by an Instron ${ }^{\circledR} 5569$ testing machine at a cross head speed of $2 \mathrm{~mm} /$ minute. 


\section{RESULTS}

\section{A. Microstructures of HPDC and MC-HPDC Samples}

The microstructures of tensile specimens produced with MC-HPDC and HPDC processes are shown in Figure 1. The alloy exhibited a typical hypoeutectic solidification structure, consisting of primary $\alpha-\mathrm{Al}$ (white in contrast) dendrites and interdendritic networks of eutectic silicon (black in contrast). The broken dendrite arms are defined as particles and their size ranges between $\sim 3-25 \mu \mathrm{m}$. The lar $\quad \geq 6 \mu \mathrm{m}$ are denoted as $\alpha_{1}$-Al or externally solidified crystals (ESCs), which are believed to form in the shot sleeve of the HPDC machine before the liquid reaches the die cavity for final solidification and fine particles with size $<6 \mu \mathrm{m}$ denoted as $\alpha_{2}-\mathrm{Al}$, which are formed inside the die cavity.

The microstructure produced by the conventional HPDC (Figure 1(a)) reveals a non-uniform microstructure with a dendritic morphology of the primary $\alpha$-Al phase. In contrast to the conventional HPDC process, the MC-HPDC process showed a fine and uniform microstructure, as shown in Figure 1(b). The well-developed dendrites are eliminated for the MC-HPDC produced sample. The cross section of tensile specimens $(6.4 \mathrm{~mm}$ diameter $)$ produced with HPDC and MC-HPDC processes are shown in Figures 2(a) and (b), respectively. A dark defect band separated by a region of fine particles at the outer surface called the "skin" and a core of segregated ESCs at the centre of the sample is observed. The spatial variation of the primary $\alpha$ Al phase fraction shown in Figure 2(c), suggests that the MC-HPDC process results in a more uniformly distributed ESC particles across the sample. When the liquid is poured into the shotsleeve, due to the large difference between the liquid metal temperature and the shot sleeve temperature, it is likely that large dendrites form in the shot-sleeve and these are referred to as ESCs. The area fraction of ESCs as a function of the possessing temperature is shown in Figure 3. By increasing the processing temperature, the area fraction of ESC is observed to decrease significantly and also Figure 3 reveals that shearing the liquid metal causes a considerable reduction in the area fraction of ESCs at all processing temperatures. Further microstructural analysis suggests that the area fraction of $\alpha_{2}$-Al particles increases with an increase in the processing temperature (total area fraction of the primary $\alpha-\mathrm{Al}=\alpha_{1}-\mathrm{Al}+\alpha_{2}-\mathrm{Al}$ ). However, quantifying the area fraction of $\alpha_{2}$-Al has not been possible due to their fine grain nature $(<6$ 
$\mu \mathrm{m})$. The shape factor for ESC particles was observed to decrease with an increase in the processing temperature.

A microstructural study of the cross section of a tensile sample (6.4 mm diameter) reveals the presence of a defect band, as shown in Figure 4(a). Outer and inner edges of the band are highlighted with circular dashed-lines. Defect band location or the skin thickness is defined here as the position along the radial distance from the casting surface to the outer edge of the band. The measured skin thickness is plotted in Figure 4(c) as a function of the processing temperature. Figures 4(c) and (d) show measurements of skin and band thickness location at four different pouring temperatures. At each temperature, since band thickness is varying from specimen to specimen, we have taken average of ten data points and the standard deviation is shown as error bar. In Al-Si alloy, the defect band is a well-defined structure which consists of the eutectic Al-Si phase (Figure 4(b)) than the primary $\alpha$-Al phase and also contains significant porosity. By applying intensive shearing the thickness of the band has been reduced significantly, in other words, the primary $\alpha-\mathrm{Al}$ particles are spread uniformly in the band region and this region does not contain well-defined edges (Figure 2(b)).

The eutectic of Al-Si alloy, under slow cooling conditions, typically consists of Si flakes or sheets. However, at relatively fast cooling rates, such as in HPDC, the Al-Si eutectic phase is much finer (around $3 \mu \mathrm{m}$ ). In addition, the size, shape and distribution of the brittle eutectic silicon phase in the final microstructure play an important role $e^{[14,15]}$ in the mechanical properties of alloys. In the present study, we observed that the eutectic silicon phase distribution has been modified by intensively shearing the liquid metal. The optical micrographs for intensively sheared samples (Figure 1(b) and Figure 2(b)) suggest that an overall microstructural refinement in the entire bulk sample occurs through an increased distribution of $\alpha$-Al particles, thus providing better uniform eutectic phase throughout the microstructure.

\section{B. Intermetallic particles}

The detrimental effects of Fe impurity to Al-alloys are due to its low equilibrium solubility in the $\alpha$-Al solid solution phase $(<0.04 \text { wt. } \%)^{[16]}$, and the associated strong tendency to form various low-symmetry Fe-bearing aluminides. Ternary Al-Fe-Si phases that are of particular importance to Al-Si based cast alloys are the hexagonal $\alpha$-AlFeSi $\left(\mathrm{Al}_{8} \mathrm{Fe}_{2} \mathrm{Si}\right.$, Pearson symbol: $h P 246$, space 
group $\mathrm{P}_{3} / m m c$ and to be referred as $\alpha-\mathrm{Al}(\mathrm{Fe}, \mathrm{Mn}) \mathrm{Si}$ in this study: Pearson symbol $c P 138$, space group $P m \overline{3}$ ) and the monoclinic $\beta$-AlFeSi $\left(\mathrm{Al}_{5} \mathrm{FeSi} \text {, monoclinic lattice }\right)^{[17, \mathrm{X} 2]}$. When these low symmetry compounds crystallise, in particular, as primary phases during solidification, they are prone to grow into long needles/plates that are extremely detrimental to both strength and ductility. ${ }^{[18, X 1]}$ The intermetallic compounds which are in a spherical shape are identified as the $\alpha-\mathrm{Al}(\mathrm{Fe}, \mathrm{Mn}) \mathrm{Si}$ phase (Figure 5(a)). Needle-shaped particles are identified as $\beta$-AlFeSi phase as shown in the inset to Figure 5(a). The primary $\alpha-\mathrm{Al}(\mathrm{Fe}, \mathrm{Mn}) \mathrm{Si}$ particles exhibit a spherical morphology when they are small, and they may develop into more complex morphologies (e.g. cross-like or star-like) with an increase in their sizes. ${ }^{[18]}$ The $\beta$-AlFeSi compounds exist as large needles or plates, which are not often observed in this alloy due to the presence of $\mathrm{Mn}^{\left[{ }^{[1]}\right.}$

The effect of shearing on the primary $\alpha$-Al solid solution phase formation was to modify its dendritic morphology into globular primary particles. Comparing sheared microstructures to that of their conventional counterparts, it is seen that the effect of shearing on the morphologies of primary $\alpha-\mathrm{Al}(\mathrm{Fe}, \mathrm{Mn}) \mathrm{Si}$ intermetallic compounds was significant. In addition, our previous investigation ${ }^{[18, \mathrm{X} 4]}$ observed that the long needle-shaped $\beta$-AlFeSi phase was largely eliminated from the microstructures of sheared samples when processed in the semi-solid state. The rough branching or star-like intermetallic particles in the HPDC samples have been transformed to a more globular shape with intensive shearing. In addition, clusters of the $\alpha$-AlFeMnSi particles are distributed more uniformly by the application of intensive shearing (Figure 5(b)).

The quantitative analysis of the intermetallic particles was focused on the $\alpha-\mathrm{Al}(\mathrm{Fe}, \mathrm{Mn}) \mathrm{Si}$ particles. The size distribution of $\alpha-\mathrm{Al}(\mathrm{Fe}, \mathrm{Mn}) \mathrm{Si}$ particles is shown for both sheared and nonsheared samples in Figure 5(c). It can be clearly seen that by applying intensive shearing their average size has been reduced to $5 \mu \mathrm{m}$ from $8 \mu \mathrm{m}$ and the narrow size distribution suggests that MC-HPDC samples have a negligible density of large $\alpha-\mathrm{Al}(\mathrm{Fe}, \mathrm{Mn}) \mathrm{Si}$ particles of a size $>14 \mu \mathrm{m}$. The absence of large particles will have a significant role in improving the mechanical properties, particularly the ductility. The result of the Quadrat method calculations are in accordance with the optical observation made from the microstructure. They are given in Figure 5(d) as a frequency scatter of the number of particulates per Quadrat, $N_{q}$, together with the corresponding theoretical curves. The magnitude of clustering affects the shape of the $N_{q}$ distribution, with a higher tendency to clustering making the $N_{q}$ distribution less symmetric. As 
proven mathematically ${ }^{[13]}$, a clustered spatial distribution follows a negative binominal model, a random spatial distribution follows a Poisson model and a regular spatial distribution model follows a binominal model. The observed particle distribution for the non-sheared samples lies closer to the negative binominal curve indicating clustering (Figure 5(a)), whereas the sheared sample particles distribution resemblance more to the Poisson and binominal curves.

\section{Porosity}

In Al-Si cast alloys depending on the processing conditions three different types of pores are generally observed which are gas pores, shrinkage pores, and entrapped gas pores. In addition, it is found that molten $\mathrm{Al}$ is very susceptible to hydrogen and this can lead to gas porosity in the final components. The shrinkage porosity frequently has been observed to be associated with the morphology and distribution of the primary $\alpha$-Al phase for hypoeutectic alloys and this type of pores are commonly observed in between coarse $\alpha$-Al primary dendrites. Porosity on the surface or just beneath will act as a stress raiser and subsequently lead to crack initiation. In the specimens produced by the MC-HPDC process, where macro and shrinkage porosity were observed only occasionally, the micro pores were found to be usually smaller than in the HPDC specimens. Samples produced by the HPDC process generally showed a level of porosity of about $\sim 1 \%$ area fraction (Figure 6), while those produced by the MC-HPDC process showed approximately $\sim 0.3 \%$ area fraction.

\section{Mechanical properties}

Figure 7 summarizes the tensile properties obtained from samples produced by HPDC and MCHPDC as a function of the processing temperature. As can be seen, MC-HPDC samples of Al-Si alloys exhibited a good combination of UTS and elongation to failure, compared to the typical tensile properties of samples produced by the conventional HPDC process as a result of the reduced porosity and defect band size combined with the replacement of coarse primary $\alpha-\mathrm{Al}$ dendrites by spherical particles in the MC-HPDC samples. Figure 7 also shows that both strength and ductility of the MC-HPDC specimens are less sensitive to the processing temperature within the present processing temperature range. 


\section{DISCUSSION}

\section{A. Grain refining}

The experimental findings in the current study clearly demonstrated that a substantial grain refinement with a uniform microstructure for the Al-Si alloy can be achieved by MC-HPDC process. The microstructure is shown to refine, for the first time, by intensive melt shearing without any involvement of a deliberate chemical addition. Samples cast from the non-sheared liquid metal exhibit large dendrites, which are non-uniform throughout the cross section of the tensile sample (Figure 1(a) and Figure 2(a)). However, by applying intensive shearing, the grain size has been substantially reduced as shown in Figure 2(b) without the addition of chemical grain refiners such as an Al-Ti-B master alloy.

The creation of an ideal condition for nucleation and ensuring a high survival of nuclei has been employed as a physical grain refining strategy in the present investigation. Hutt and StJohn have discussed the five major available theories and critically assessed the applicability of the proposed mechanisms. ${ }^{[19]} \mathrm{A}$ literature review suggests that with the absence of a grain refiner (where constitutional undercooling derived nucleation is important), big bang (also known as free chill crystals or a wall mechanism) and detachment of dendrites mechanisms are the primary contributions to the creation of equiaxed grains. ${ }^{[8]}$

A counter-argument for grain refinement is possibly the enhanced formation of heterogeneous nuclei induced by shearing. The MCAST unit consists of a pair of twin screws, which is capable of delivering very high intensity shear and a high level of turbulence. In addition, inside the MCAST unit the entire melt is broken up into very small packets that are in intimate contact with the screw surfaces and barrel resulting in very efficient heat transfer. ${ }^{[9]}$ It appears that shearing enhances the homogeneity in the alloy melt with respect to temperature, composition and uniformly distributes the nucleating agents throughout the melt. A melt with a uniform temperature in combination with fast heat extraction during the solidification create the ideal conditions for copious nucleation and ensures the survival of nuclei which can significantly increase the number of effective nucleation events. The result shows that intensive shearing and high turbulence have the potential to distribute foreign particles such as intermetallic particles, oxide films and clusters into individual particles with a fine size and a narrow size 
distribution. ${ }^{[10]}$ However, wettability is one of the essential conditions for a foreign particle to act as a potent nucleating site. It is believed that wetting of foreign particles in the liquid metal is enhanced by an intensive shearing condition and their uniform distribution act as heterogeneous nuclei. ${ }^{[10, X 3]}$

\section{B. Mechanism for band formation}

In conventional HPDC cast sample (Figure 2), a higher solid fraction of ESC particles is concentrated in the centre of the die cast samples. As we move from the centre toward the wall the solid fraction of ESC particles are decreased (Figure 2(c)). As is known when the solid fraction of particles is increased above the coherency point, the shear strength increases as a function of $f_{s}$ (solid fraction). Once ESC particle dendrite network forms and hence starts to partly interlock the growth and required higher energy to deform it is such that shearing occurs with high resistance. This leads to a defect band between the concentrated ESC particle region and the skin. In particular, in the conventional HPDC process, the ESC particle solid fraction is mainly governed by the temperature of the melt in the shot sleeve and is influenced by several parameters, such as liquid metal superheat, the heat transfer coefficient, and surface properties of the shot sleeve and alloy composition. The mechanism for band formation and effect of HPDC process parameters on defect band are explained in Ref. ${ }^{[4-6,20]}$

By contrast, the sheared melt will have a uniform temperature, composition and well-dispersed nucleation sites, which results in the formation of considerably smaller solid fraction of ESC particles (Figure 4) which are well distributed throughout the volume of the MC-HPDC, cast specimens (Figure 2(c)). At low solid fractions, the strength increases at a relatively low rate.

When the solid fraction along the shear plane is reduced to below $f_{s}^{\text {peak }}$, shearing can occur with less resistance. This shearing strength is further reduced when the ESC particle morphology is spherical in shape and considerable liquid flow between the particles is possible, which helps in the final solidification to reduce the area fraction of porosity in cast specimens.

The experimental results confirm this mechanism with respect to a variation of the pouring temperature. Figures 5(c) and (d) show the generated defect band position from the die wall and its thickness with respect to the processing temperature of HPDC and MC-HPDC specimens. 
The results clearly show that the higher fraction of ESC particles in the conventional HPDC sample generate a defect band more close to the die wall. From the experimental results it is also noticeable that by applying intensive shearing to the Al-Si hypoeutectic liquid a reduced defect band size and a uniform distribution of ESC particles allows the band position to be generated closer towards the centre, which has a direct relation with the mechanical properties of the cast samples.

\section{Porosity}

The current understanding is that porosity in $\mathrm{Al}$ alloys is due to both solidification shrinkage and gas porosity. Hydrogen is the only gas to be readily dissolved to a significant level in liquid Al. Hydrogen contents of $\sim 0.65$ and $0.034 \mathrm{ml} / 100 \mathrm{~g}$ in the liquid and solid phase have been reported for pure $\mathrm{Al} .^{[21]}$

Most metals shrink during the phase transformation from the liquid to the solid and this is the main reason for the formation of macro and micro shrinkage porosity in castings. Macro shrinkage or volumetric shrinkage is typically of the order of $6 \%$ for pure $\mathrm{Al}$ alloys ${ }^{[22]}$ and it varies with the addition of alloying elements. According to Campbell ${ }^{[23]}$ there are five different feeding mechanisms which can take place to compensate for volumetric shrinkage during the different stages of solidification. Micro-shrinkage porosity formation is high during the interdendritic and solid feeding stage (the last stages of solidification) so that generally micro shrinkage porosity is found in the interstices of dendrites and in the volumes which solidify last.

In addition, the current investigation shows the application of high intensive shearing to a liquid Al melt prior to solidification reduces the formation of micro porosity under the same casting conditions for the Al-Si alloy studied. It is necessary to mention here that the liquid melt will be exposed to air for a longer time during MCAST process compared to the conventional process. It is expected that than $\mathrm{Al}$ melt would absorb a certain amount of hydrogen gas which might form gas bubbles. The presence of larger size pores is observed in the conventional sample when compared to MCAST sample. This finding suggests that gas bubbles that were already formed in the liquid melt may have collapsed and/or dispersed into a smaller size by the application of high intensive shearing, which hence resulted in the formation of smaller and less micro porosity. 
As suggested by Campbell ${ }^{[23]}$, and Gupta et $a l^{[24]}$ an oxide film can be a potential site for the formation of gas and shrinkage porosity in conventional cast samples. Generally, oxide films present in as-cast $\mathrm{Al}$ alloys are there as bifilms, and are easy for gas entrapment between the contacting dry side oxide films ${ }^{[23]}$. In our previous studies Fan et al. $^{[10]}$, found that when intensive shearing was applied to the melt, the oxide film will be broken up into individual particles and dispersed uniformly in the liquid melt. Furthermore, it is also understood that intensive shearing can force the liquid metal to wet the oxide particles by "forced convection". The presence of wetted individual oxide particles in the MCAST sample can no longer be potential sites for the formation of porosity and may lead to diminish the porosity.

As shown in Figure 7, the strength and elongation are considerably increased for samples produced with the MC-HPDC process due to the refined microstructure. The fracture strength, $\sigma_{f}$ of the materials is exceeded when various factors such as the size, shape, distribution and volume fraction of the particles are considered. Particles with a larger size will lead to fracture at a smaller $\sigma_{f}$. Fracture mechanics suggests that $\sigma_{f}$ can be approximated by ${ }^{[25,26]}$ :

$$
\sigma_{f}=\sqrt{\pi E \gamma_{s} / D}
$$

where $\gamma_{s}$ is the specific surface energy, $D$ is the diameter of the particles and $E$ is Young modulus. Therefore, the morphology of the primary $\alpha$-Al, eutectic silicon, intermetallic particles and porosity play a very important role in the mechanical properties of the Al-Si alloy. The reduced particle size, with application of intensive shearing will contribute to an improved fracture strength of the alloy. However, strength and elongation are the most common properties that are used to characterize die-casting components. These properties can be severely affected by intermetallics, skin thickness, band position and porosity. As mentioned in Section III, application of shearing was able to reduce the grain size, porosity and significantly diffuse the defect band by increasing the uniformity of the ESC particles. In addition, as shown in the Figure 5, shearing the liquid is able to alter the morphology and improve the size distribution of the intermetallic particles. 


\section{CONCLUSION}

The morphology, defects and microstructural refinement of a hypoeutectic Al-Si casting alloy have been investigated under dynamic intensive shearing conditions above the liquidus temperature and compared with a conventional HPDC process. The following conclusions were obtained from the experimental results:

(1) Intensive melt shearing provides significant grain refining of primary $\alpha$-Al and a uniform grain size over entire casting specimen.

(2) Intensive shearing improved the distribution of the $\alpha-\mathrm{Al}(\mathrm{Mn}, \mathrm{Fe}) \mathrm{Si}$ intermetallic phase with a narrow size distribution and the average $\alpha-\mathrm{Al}(\mathrm{Mn}, \mathrm{Fe}) \mathrm{Si}$ intermetallic particle size was reduced to $5 \mu \mathrm{m}$ from $8 \mu \mathrm{m}$.

(3) Defect bands were observed to be present in both with and without sheared HPDC tensile specimens. However, intensive shearing distributes ESCs more uniformly, provides an ideal condition to nucleate primary $\alpha-\mathrm{Al}$ which is spherical in shape and significantly reduces the defect band size and porosity.

(4) The possible mechanisms for the reduced porosity formation under MCAST unit are:

(i) Gas bubbles already in the molten liquid can collapse and/or the dispersed into smaller bubbles by application of high intensive shearing.

(ii) Potential nucleation sites of dry sided oxide films for porosity can be broken up into fully-wetted oxide particles that are no longer potential nucleation sites.

(iii) Formation of a fine equiaxed grain structure enhances liquid mobility in the last volumes of liquid to be solidified.

\section{ACKNOWLEDGMENTS}

This study has been funded by the EPSRC. The authors thank BCAST members for help conducting experiments. 


\section{REFERENCES}

[1] I.J. Polmear: Light alloys, third ed., Butterworth-Heinemann, Oxford, 1995.

[2] M. Dash and M. Makhlouf: J. Light Metals, 2002, vol. 2(1), pp. 251-65.

[3] A.C. Street: The Die-casting Book, second ed., Portcullis Press Ltd., Surry, England, 1986, pp. 195-223.

[4] C.M. Gourlay, H.I. Laukli, and A.K. Dahle: Metall. Mater. Trans. A, 2007, vol. 38A, pp. $1833-44$.

[5] A.K. Dahle and D.H. StJohn: Acta Mater., 1999, vol. 47, pp. 31-41.

[6] A.K. Dahle, Y.C. Lee, M.D. Nave, P.L. Schaffer, and D.H. StJohn: J. Light Metals, 2001, vol. 1(1), pp. 61-72.

[7] Z. Fan, M.J. Bevis, and S. Ji: PCT Patent, WO 01/21343 A1.(1999).

[8] Z. Fan: Inter. Mater. Rev., 2002, vol. 47, pp. 49-85.

[9] A. Das, G. Liu, and Z. Fan: Mater. Sci. Eng. A, 2006, vol. 419A, pp. 349-56.

[10] Z. Fan, Y. Wang, M. Xia, and S. Arumuganathar: Acta Mater., 2009, vol. 57, pp. 489101 .

[11] H. R. Kotadia, E. Doernberg, J. B. Patel, Z. Fan, and R. Schmid-Fetzer: (2009), Metall. Meter. Trans. A, 2009, vol. 40A, pp. 2202-11.

[12] H. Tang, L.C. Wrobel, and Z. Fan: Appl. Phys. A, 2005, vol. 81A, pp. 549-59.

[13] P.A. Karnezis, G. Durrant, and B. Cantor: Mater. Charact., 1998, vol. 40, pp.97-09.

[14] R. Elliott: Eutectic solidification processing, Butterworths \& Co., London, 1984: pp.55-88, pp.157-229.

[15] J. R. Davish (Ed.): Aluminum and aluminum alloys, ASM International, OH, 1993.

[16] L.F. Mondolfo: Aluminum alloys: structure and properties, Butterworths \& Co., London, 1976.

[17] P. Villars and L.D. Calvert (ed.): Pearson's Handbook of Crystallographic Data for Intermetallic Phases, second ed., ASM International, Materials Park, OH, 1991.

[18] X. Fang, G. Shao, Y.Q. Liu, and Z. Fan: Mater. Sci. Eng. A, 2007, vol. 445-446A, pp. $65-72$.

[19] J. Hutt and D. StJohn: Int. J. Cast Met. Res., 1998, vol. 11, pp. 13-22. 
[20] C.M. Gourlay, H.I. Laukli, and A.K. Dahle: Metall. Meter. Trans. A, 2004, vol. 35A, pp. 2881-91.

[21] D.M. Stefanescu, B.K. Dhindaw, S.A. Kacar, and A. Moitra: Metall. Meter. Trans. A, 1988, vol. 19A, pp. 2847-55.

[22] J.R. Brown: Foseco Non-Ferrous Foundaryman's Handbook, eleventh ed., ButterworthHeinemann, Oxford, UK, 1999.

[23] J. Campbell: Castings, Butterworth-Heinemann, Oxford, UK, 1997.

[24] A.K. Gupta, B.K. Saxena, S.N. Tiwari, and S.L. Malhotra: J. Mate. Sci., 1992, vol. 27, pp. 853-62.

[25] D.A. Curry and J.F. Knott: Metar. Sci., 1979, vol. 13, pp. 341-45.

[26] F.T. Lee, J.F. Major, and F.H. Samuel: Metall. Meter. Trans. A, 1995, vol. 26A, pp. 1553-70.

[X1] S. Gowri and F.H Samuel: Metall. Meter. Trans. A, 1994, vol. 25A, pp. 437-48.

[X2] V.G. Rivlin and G. V. Raynor: Inter. Mater. Rev., 1981, No. 3, pp. 133-52.

[X3] S. Tzamtzis, H. Zhang, N. Hari Babu, Z. Fan: Mater. Sci. Eng. A, 2010, vol. 527A(12), pp. 2929-34.

[X4] H.R. Kotadia, N. Hari Babu, H. Zhang, and Z. Fan: Mater. Lett., 2010, vol. 64(6), 67173.

[X5] Z. Fan, M. Xia, H. Zhang, G. Liu, J. B. Patel, Z. Bian, I. Bayandorian, Y. Wang, H. T. Li and G. M. Scamans: J. Cast Met. Res., 2009, vol. 22(1-4), pp. 103-07. 


\section{Table Captions}

Table 1.Chemical composition of Al-9.4\%Si alloy ingot used in this study (in wt.\%)

Table 2. HPDC processing parameters used for Al-9.4\% Si alloy. HPDC machine with 280 ton capacity used for this study.

\section{Figure Captions}

Fig. 1. Optical micrographs of Al-9.4Si samples produced by (a) HPDC and (b) MC-HPDC processes. Note that these are taken from etched surfaces. The primary $\alpha$-Al dendrites can be clearly seen in samples produced by HPDC while samples produced by MC-HPDC are virtually free of primary $\alpha$-Al dendrites. It can be seen that the MC-HPDC process produces a finer and more uniform microstructure in comparison with HPDC. Primary dendritic fragments $\left(\alpha_{1}\right)$ that are formed in the shot sleeve and fine spherical particles $\left(\alpha_{2}\right)$ formed inside the die cavity can be seen.

Fig. 2. Cross-sectional images of the microstructures of the tensile samples produced by (a) HPDC process, showing a defect band and large central grains with segregated ESC particles and (b) MC-HPDC process. The bright phase in both images is primary $\alpha$-Al and the black contrast regions are the eutectic phase regions. (c) Spatial variation of area fraction of primary $\alpha-\mathrm{Al}$ particles (sum of $\alpha_{1}$ and $\alpha_{2}$ ) across the tensile specimen cross section. Each data point represents the measured area fraction of primary $\alpha-\mathrm{Al}$ in a total area of one micrograph frame measuring $850 \mu \mathrm{m} \times 1250 \mu \mathrm{m}$.

Fig. 3. Area fraction of the ESC particles as a function of the processing temperature.

Fig. 4. Typical optical micrographs of Al-9.4\% Si alloy produced by the HPDC process (a) across the cross sectional surface (b) higher magnification images at various locations (i) outside the 
band (ii) inside the band, and (ii) centre of the tensile specimen; (c) and (d) are band thickness and skin thickness as a function of processing temperature.

Fig. 5. Optical micrographs taken from samples prior to etching to reveal the intermetallic phase particles. (a) Non-sheared produced sample (inset shows needle-shaped $\beta$-AlFeSi intermetallics phase) and (b) sheared produced sample. (c) $\alpha$-AlSiMnFe particle size distribution curves for both samples (d) Particle group number, $N q$ (number of particles per Quadrat) distribution. Solid lines are fits to various statistical distribution curves. To plot these curves in (c), 8 micrographs were taken randomly along the cross-section and analysed where (i) and (ii) stand for $\alpha$ $\mathrm{AlSiMnFe}$ and $\beta$-AlFeSi, respectively. The processing temperature was $630^{\circ} \mathrm{C}$.

Fig. 6. Measured porosity as a function of the processing temperature.

Fig. 7. Tensile properties (a) elongation to failure and (b) UTS (ultimate tensile strength) as a function of the processing temperature. 
Table. 1

\begin{tabular}{cccccccc}
\hline $\mathrm{Al}$ & $\mathrm{Si}$ & $\mathrm{Mg}$ & $\mathrm{Mn}$ & $\mathrm{Fe}$ & $\mathrm{Zn}$ & $\mathrm{Cu}$ & Other impurity \\
\hline Balance & 9.38 & 0.49 & 0.26 & 0.80 & 1.02 & 2.31 & $<0.09$ \\
\hline
\end{tabular}

Table. 2

\begin{tabular}{ccccccc}
\hline Melt & Superheat & Feeding & Intensive & Pressure & Die & Cooling \\
Temp. & & Pressure & pressure & trigger & Temperature & time \\
& & & & & & \\
\cline { 1 - 1 } 730 & 130 & $84($ Bar $)$ & 119 (Bar) & $70($ Bar $)$ & $220\left({ }^{\circ} \mathrm{C}\right)$ & $30(\mathrm{~s})$ \\
$\left({ }^{\circ} \mathrm{C}\right)$ & & & & & & \\
\hline
\end{tabular}



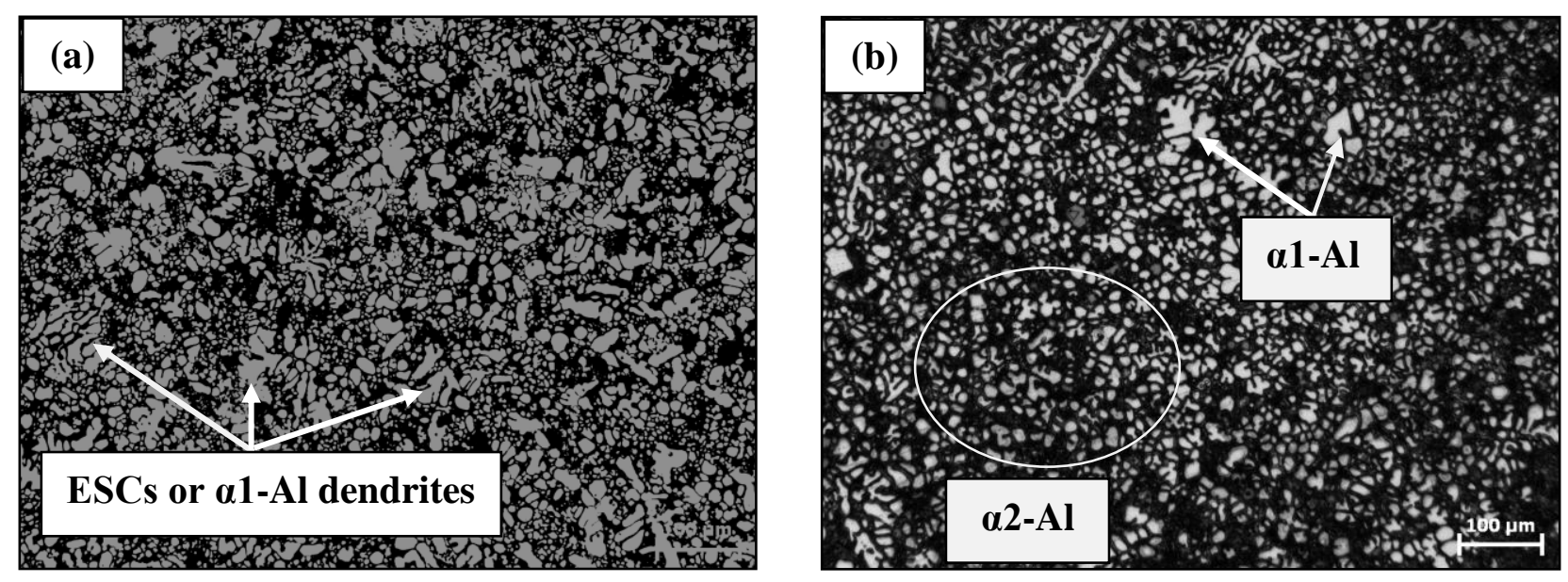

Fig. 1. 

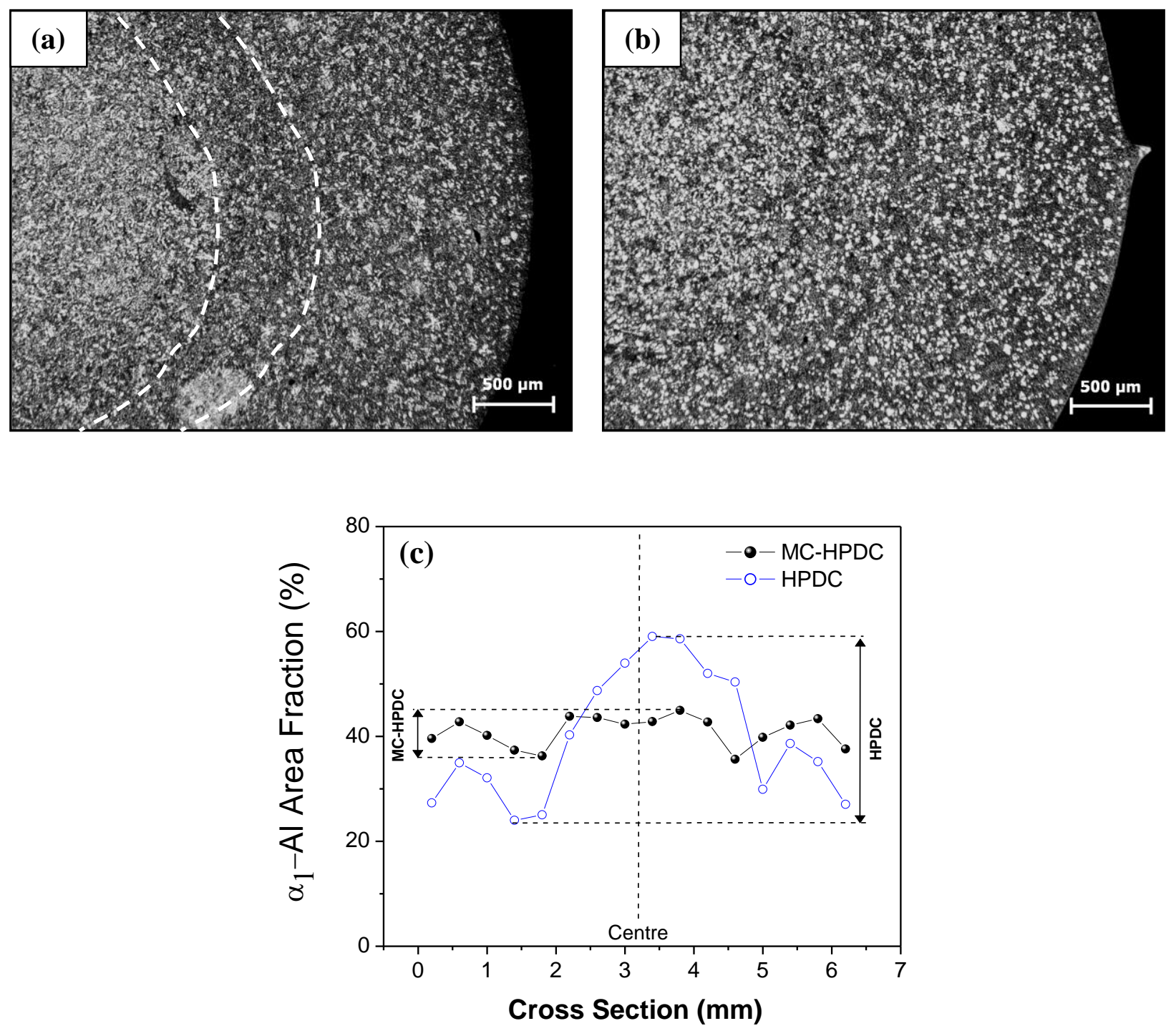

Fig. 2. 


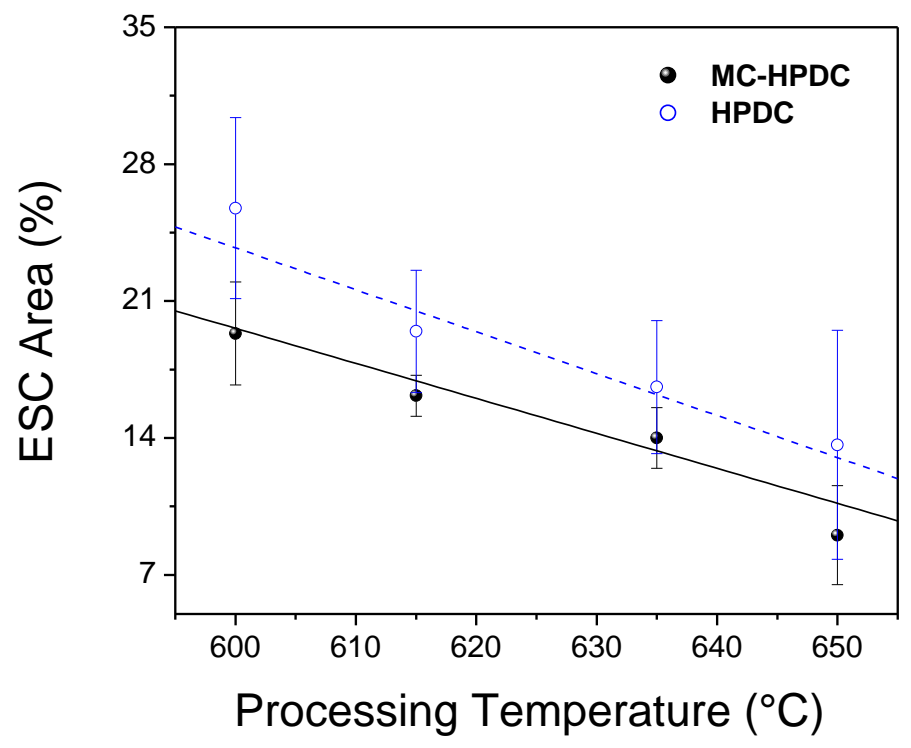

Fig. 3. 
(a)
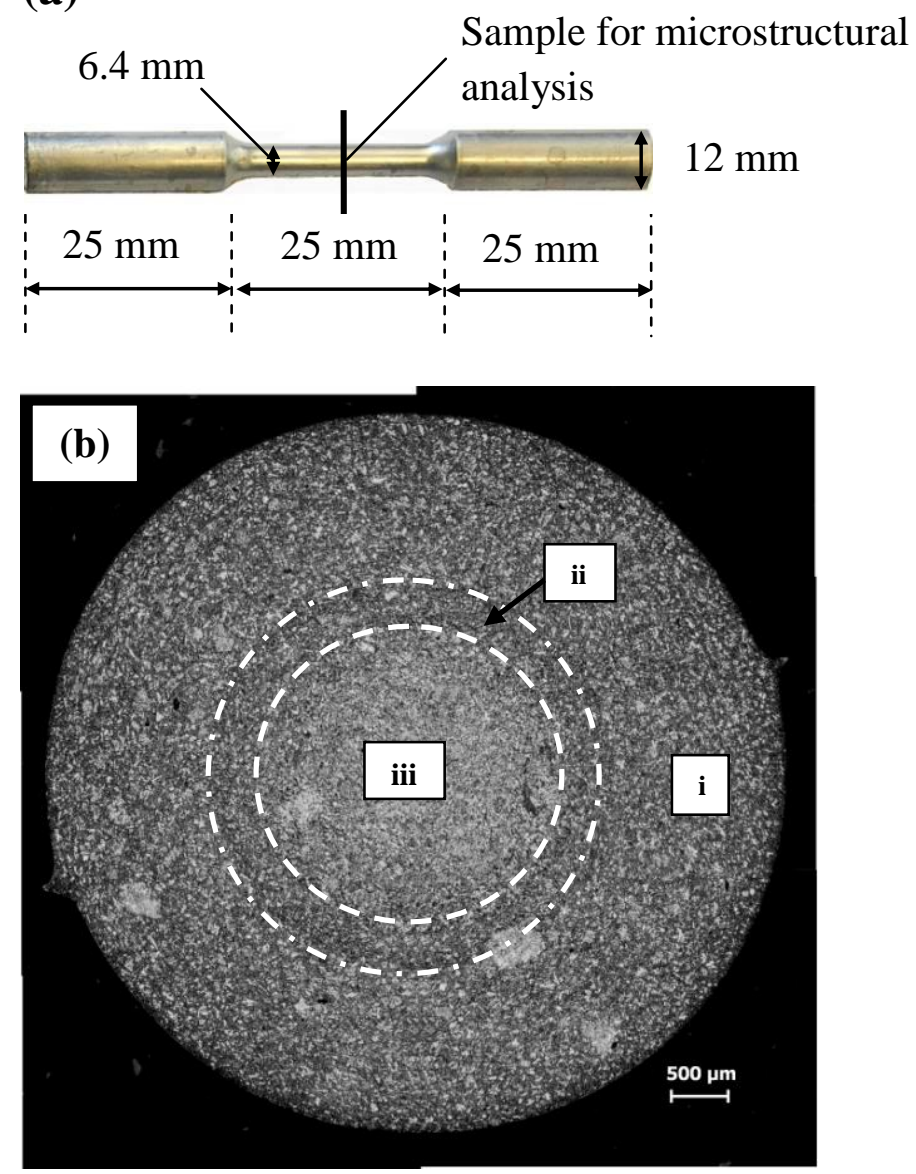

(c)
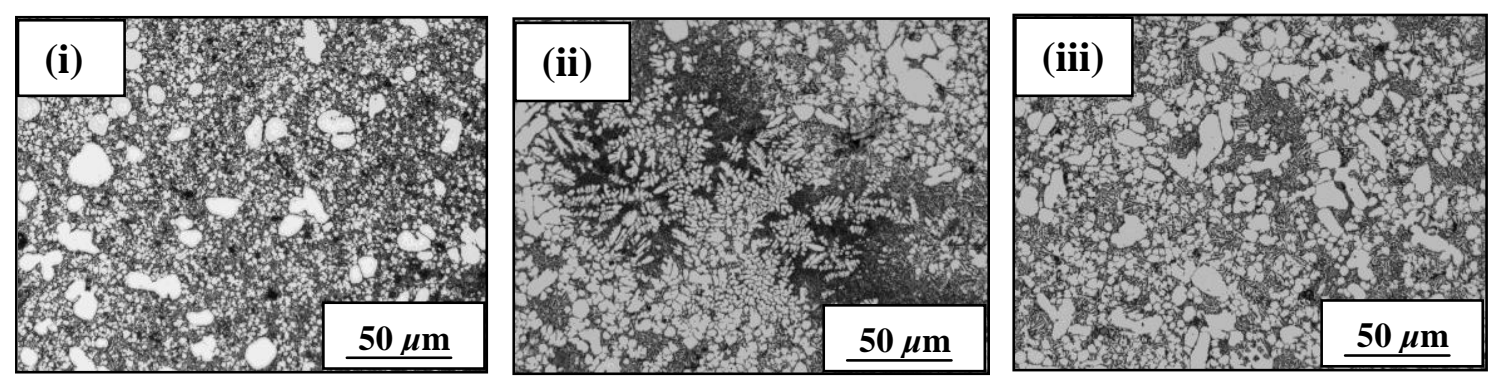

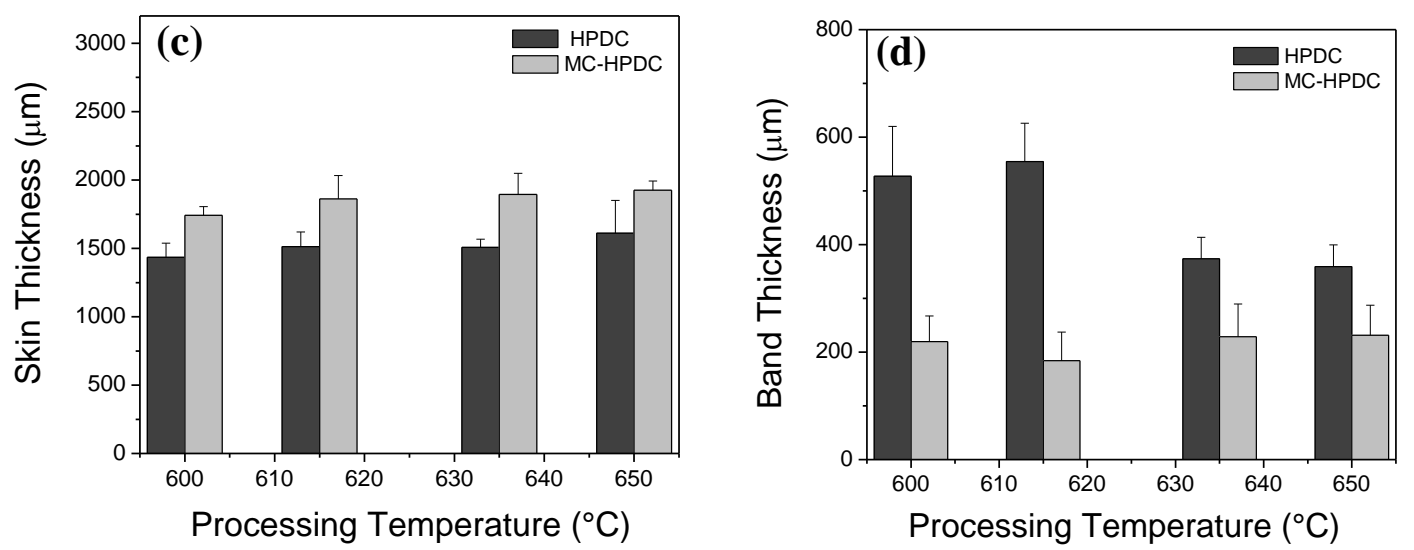

Fig. 4. 

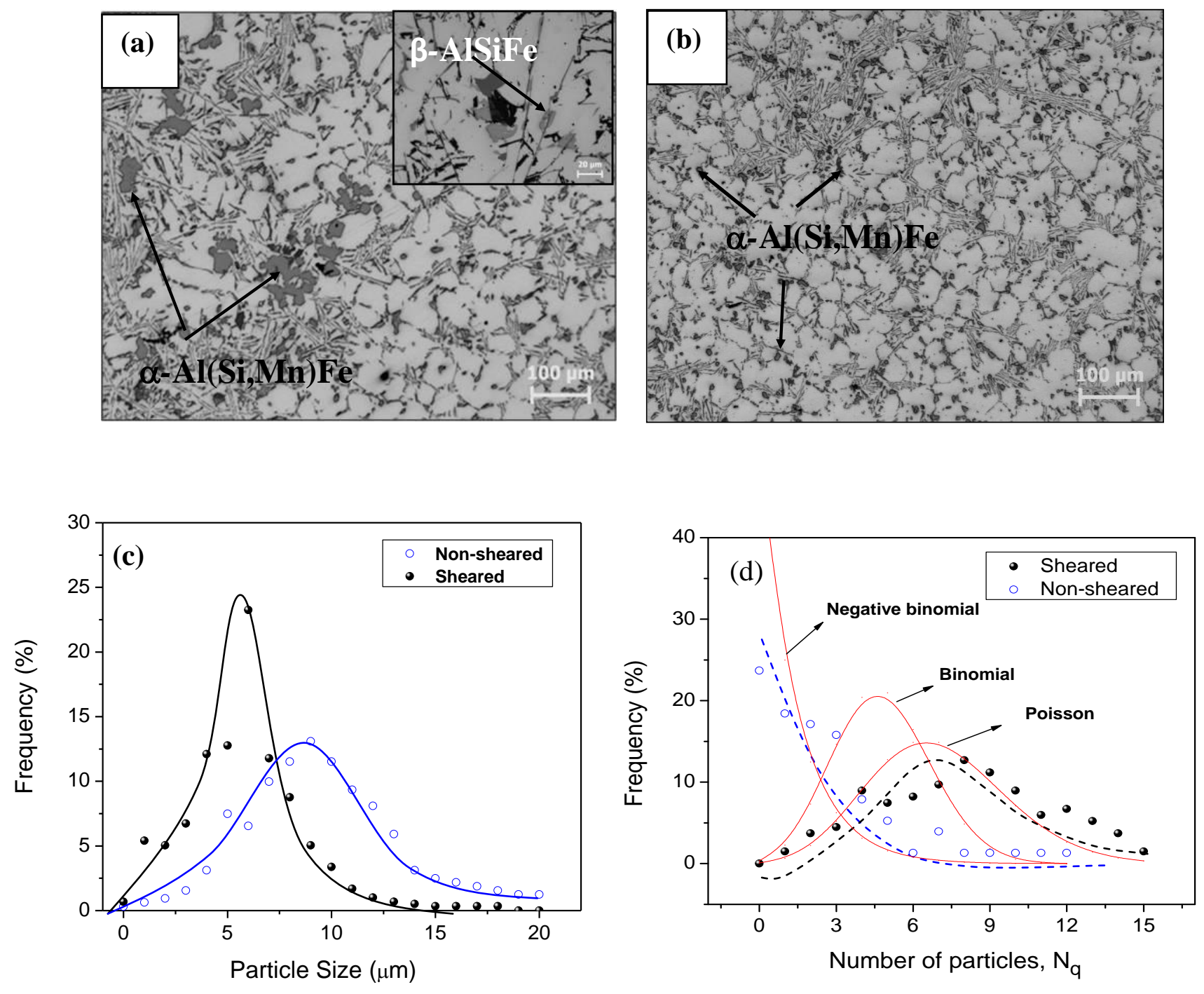

Fig. 5. 


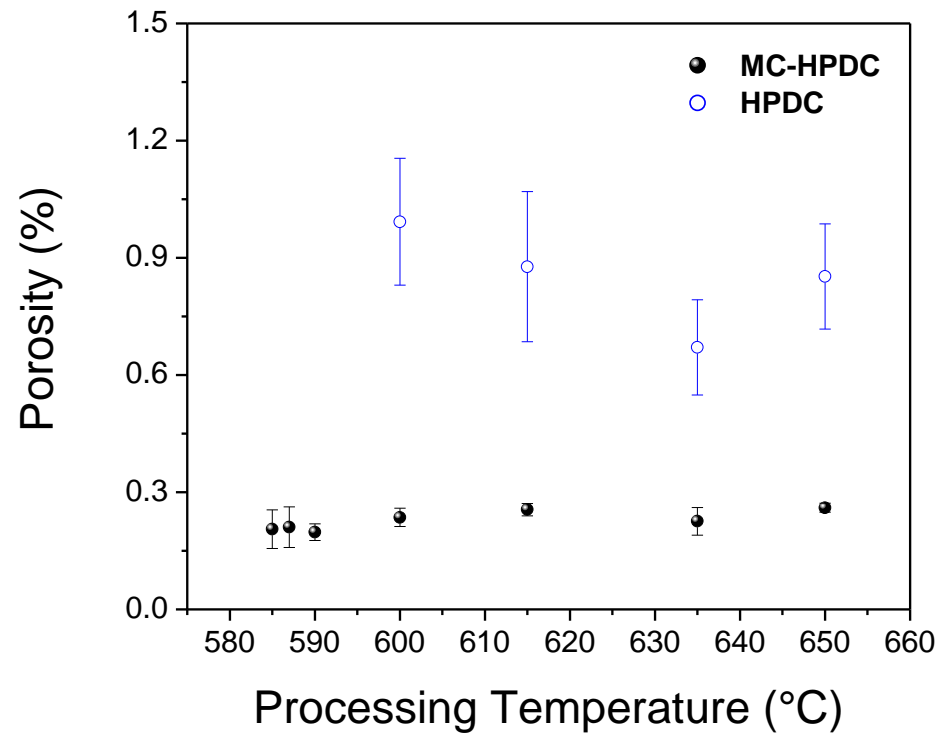

Fig. 6. 

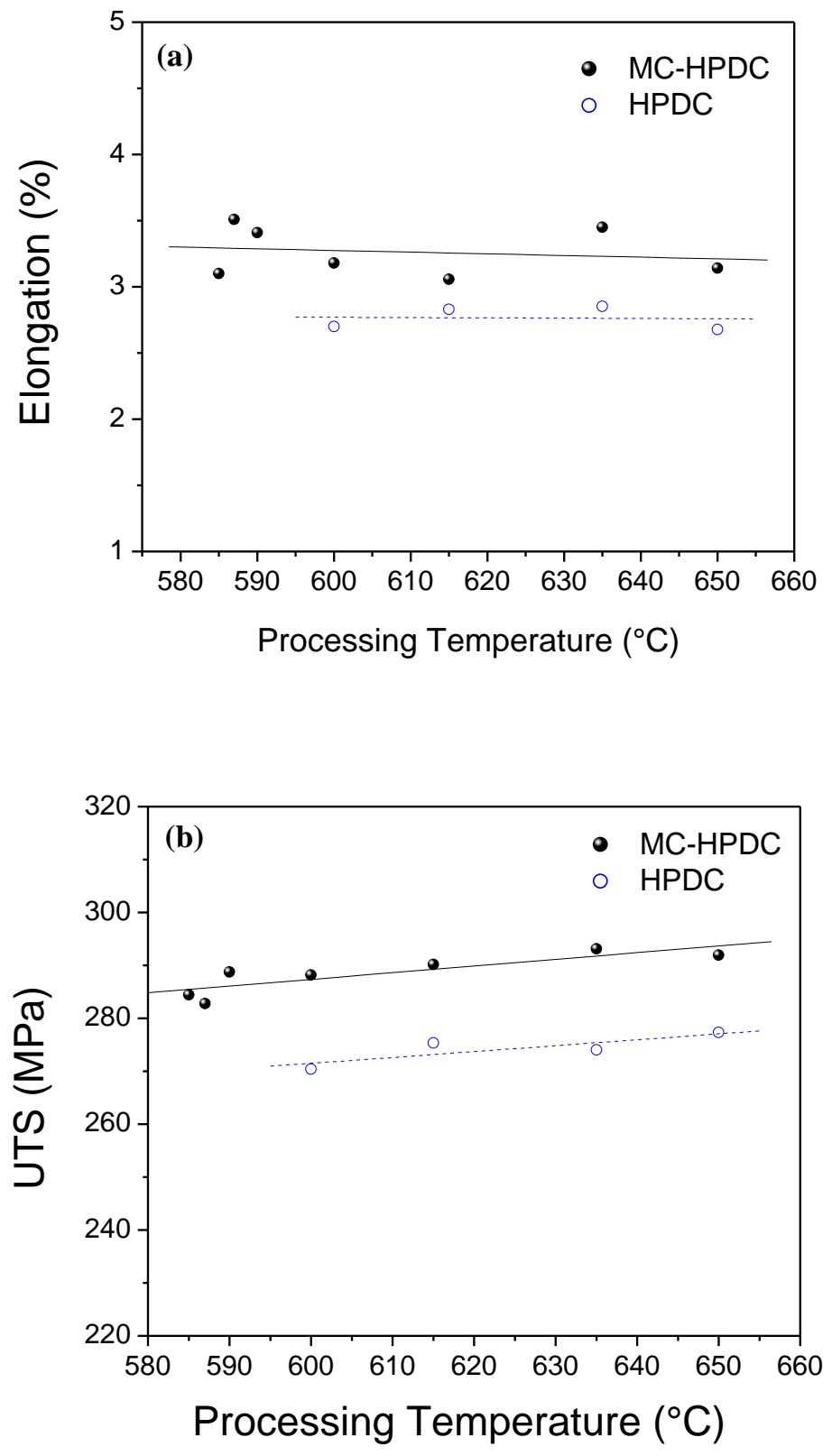

Fig. 7. 